\title{
Escala Diagramática para Avaliação da Severidade da Mancha Foliar do Eucalipto Causada por Quambalaria eucalypti*
}

\author{
Gabriela C. G. Andrade, Acelino C. Alfenas, Reginaldo G. Mafia, Luiz A. Maffia \\ \& Rivadalve C. Gonçalves
}

Departamento de Fitopatologia, Universidade Federal de Viçosa, CEP 36570-000, Viçosa, MG, e-mail: aalfenas@ufv.br

(Aceito para publicação em 31/05/2005)

Autor para correspondência: Acelino Couto Alfenas

ANDRADE, G.C.G., ALFENAS, A.C., MAFIA, R.G., MAFFIA, L.A. \& GONÇALVES, R.C. Escala diagramática para
avaliação da severidade da mancha foliar do eucalipto causada por Quambalaria eucalypti. Fitopatologia Brasileira 30:504-
509. 2005.

RESUMO

A mancha foliar, causada por Quambalaria eucalypti, é atualmente uma das principais doenças do eucalipto (Eucalyptus spp.) na fase de viveiro. Devido à sua recente constatação no Brasil, pouco se conhece sobre a epidemiologia e o controle dessa doença. Em função da necessidade de métodos padronizados e confiáveis para sua quantificação foi elaborada uma escala diagramática contendo oito níveis $(0,4 ; 1 ; 2 ; 4 ; 8 ; 16$; 32 e 49\%) de severidade. Na sua validação, quatro avaliadores inexperientes e quatro experientes avaliaram folhas com diferentes níveis de severidade, inicialmente sem o uso da escala e posteriormente com o seu uso, sendo as estimativas comparadas quanto à acurácia e precisão. Com a utilização da escala, os avaliadores apresentaram melhores níveis de precisão e acurácia. Da mesma forma, após o treinamento, os níveis também foram melhorados, principalmente para os avaliadores inexperientes. Erros na quantificação da severidade da doença ocorreram com maior freqüência entre 15 e 30\% de severidade, independentemente da experiência dos avaliadores.

Palavras-chave adicionais: patometria, escala diagramática, severidade, eucalipto, Quambalaria eucalypti.

\begin{abstract}
Diagrammatic scale for assessment of eucalyptus leaf spot severity caused by Quambalaria eucalypti

The leaf spot, caused by Quambalaria eucalypti, is presently one of the most serious diseases in eucalyptus (Eucalyptus spp.) nurseries in Brazil. Since the disease was only reported recently in Brazil, little is known about its epidemiology and control. As standardized and precise methods are needed for the disease severity evaluations, a diagrammatic scale containing eight levels $(0,4 ; 1 ; 2 ; 4 ; 8 ; 16 ; 32$ and $49 \%)$ of severity was developed in this study for the disease quantification. For the scale validation four inexperienced and four expert appraisers scored leaves with different levels of severity, initially without the use of the scale and later on with its use. The estimates were compared for accuracy and precision. Using of the scale the appraisers were able to get better levels of precision and accuracy. After training, the levels of precision and accuracy were also increased, mainly for the inexperienced appraisers. The greatest errors in the disease evaluations were observed between levels 15 and 30\% of severity.
\end{abstract}

Additional keywords: patometry, diagrammatic scale, severity, eucalypt, Quambalaria eucalypti.

\section{INTRODUÇÃO}

O fungo Quambalaria eucalypti (Wingfield, Crous \& Swart) Simpson (sin. Sporothrix eucalypti Wingfield, Crous \& Swart) foi constatado no Brasil, pela primeira vez em 2000, na região de Barra do Ribeiro - RS (Alfenas et al., 2001). Atualmente, encontra-se disseminado nas principais regiões eucaliptocultoras do país, podendo causar perdas significativas na produção de mudas clonais de eucalipto (Eucalyptus spp.) (Alfenas et al., 2004). O fungo provoca manchas foliares e anelamento de hastes e de brotações em mudas nas fases de crescimento e rustificação e em minecepas de Eucalipto em minijardim clonal, destinadas à produção de propágulos para enraizamento, especialmente nas épocas

\footnotetext{
*Parte da Dissertação de Mestrado da primeira autora. Universidade Federal de Viçosa (2004).
}

mais quentes do ano. Sobre as lesões de coloração marrom a marrom escuras, forma-se uma massa esbranquiçada de estruturas do fungo, lembrando pústulas de ferrugem branca. A abundante massa de esporos secos produzidos torna o fungo de fácil disseminação pelo vento, seja no campo ou por correntes de ar forçado nas casas de enraizamento (Alfenas et al., 2004). Embora Q. eucalypti seja atualmente um dos principais patógenos associados à propagação clonal do eucalipto, no Brasil, não existem métodos de quantificação da doença, essenciais nos estudos epidemiológicos e de controle.

Uma análise detalhada dos objetivos freqüentemente define os critérios para se escolher o método para avaliação da doença. Assim, métodos adequados devem ser escolhidos de forma criteriosa a fim de melhorar o grau de acurácia, precisão e repetibilidade das avaliações (Gaunt, 1987). Tais medidas são essenciais na quantificação da doença no espaço 
e no tempo (Zadoks, 1972). O método de avaliação varia com o agente etiológico e com a característica espacial da doença (Gaunt, 1995). No caso de doenças foliares, a severidade é a variável mais utilizada, sendo que sua avaliação é, normalmente, feita de forma subjetiva por meio de análises visuais e, por conseguinte, as escalas diagramáticas tornam-se ferramentas fundamentais em tais estudos (Godoy et al., 1997). Entre as características de uma boa escala diagramática estão: a facilidade de uso, a sua aplicabilidade sob ampla extensão de condições com resultados reproduzíveis e, a existência de intervalos que representem todos os estádios de desenvolvimento da doença (Berger, 1980). Assim, na construção de uma escala, alguns aspectos importantes devem ser considerados, como: a) os limites superiores e inferiores da escala devem corresponder, respectivamente, à máxima e mínima intensidade da doença observada no campo; b) os sintomas devem ser os mais próximos possíveis dos observados em plantas e; c) nos níveis intermediários de doença devem ser consideradas as limitações de acuidade do olho humano definidas pela lei de estímulos-resposta de Weber-Fechner, na qual a acuidade visual é proporcional ao logarítmo da intensidade do estímulo (Horsfall \& Barrat, 1945; Horsfall \& Cowling, 1978; Nutter \& Schultz, 1995).

O sucesso na utilização de escalas diagramáticas depende da sua qualidade e da experiência e percepção visual de cada indivíduo. Os graus de precisão e acurácia variam com o avaliador e necessitam ser considerados no processo. No aprimoramento da habilidade do avaliador existem “softwares” que possibilitam treinamento prévio, minimizando assim a subjetividade das avaliações (James \& Teng, 1979; Tomerlin \& Howell, 1988; Newton \& Hackett, 1994; Nutter \& Schultz, 1995).

Existem escalas diagramáticas para avaliação da severidade de doenças em várias culturas agronômicas, como feijoeiro (Phaseolus vulgaris L.) (Mora-Brenes, 1989; Sartorato, 1989; Stonehouse, 1994; Godoy et al., 1997; Díaz et al., 2001), inhame (Dioscorea cayennensis Lam.) (Michereff et al., 2000), citrus (Citrus spp.) (Amorim et al, 1993; Rodrigues et al., 2002), cana-de-açúcar (Saccharum officinarum L.) (Amorim et al., 1987), tomateiro (Lycopersicon esculentum Mill.) (Boff et al., 1991), abacaxi [Ananas comosus (L.) Merr.] (Rohrbach \& Schimitt, 1994), alface (Lactuca sativa L.) (O’ Brien \& van Bruggen, 1992), cereais (James, 1971; Duveiller, 1994) entre outras. Entretanto, para doenças florestais, especialmente para o eucalipto, ainda são escassos os trabalhos para elaboração de escalas, estando disponíveis apenas duas, uma para avaliação da severidade da bacteriose (Gonçalves, 2003) e a outra da ferrugem do eucalipto (Junghans et al., 2003). Assim, o presente trabalho foi realizado objetivando a elaboração de uma escala diagramática para quantificação da intensidade da mancha foliar causada por Q. eucalypti.

\section{MATERIAL E MÉTODOS}

\section{Definição dos níveis de severidade}

Coletaram-se 200 folhas de eucalipto, aleatoriamente, em viveiros, apresentando grande variação da severidade da doença. As folhas, após a herborização, foram fotografadas individualmente utilizando-se uma câmera fotográfica digital, e as imagens com resolução de 300 dpi foram então transferidas para um microcomputador. Em seguida, cada folha foi analisada quanto à proporção de área lesionada, utilizando-se o programa Quant (Vale et al., 2003), obtendose assim a severidade real da doença em termos percentuais. Os níveis intermediários de severidade da escala foram determinados de acordo com a lei de Weber-Fechner de acuidade visual. A partir dos valores obtidos, estabeleceu-se a escala diagramática.

\section{Validação da escala}

A validação da escala foi realizada por oito pessoas, sendo quatro experientes e quatro inexperientes. Cada grupo analisou 50 fotografias de folhas com diferentes níveis de severidade da doença. Através da análise de regressão linear, os dados estimados pelos avaliadores, com e sem o uso da escala, foram comparados com os dados reais de severidade obtidos com o auxílio do programa Quant. Assim, foi determinado o desempenho dos avaliadores quanto à precisão das estimativas obtidas pelo coeficiente de determinação $\left(R^{2}\right)$ e pela acurácia e variância dos erros absolutos (severidade real vs. severidade estimada) (Godoy et al., 1997; Nutter \& Schultz, 1995).

\section{Influência do treinamento na acurácia e precisão das avaliações}

Uma terceira avaliação foi realizada, visando determinar a eficácia do treinamento dos avaliadores na acurácia e precisão das avaliações da severidade da mancha foliar com o uso da escala diagramática. Um dia após a primeira avaliação, os mesmos avaliadores foram submetidos a um treinamento de $30 \mathrm{~min}$, no qual 60 folhas com diferentes níveis de severidade foram organizadas e apresentadas na forma de slides. Após o treinamento, os avaliadores também divididos em dois grupos, conforme estabelecido anteriormente, realizaram uma nova avaliação quanto à severidade em 50 folhas distintas. Após a avaliação, compararam-se os dados estimados pelos dois grupos com os dados reais obtidos com o auxílio do programa Quant, determinando-se, assim, o efeito do treinamento na acurácia e precisão dos avaliadores.

Ao final das avaliações, os dados foram analisados com o auxílio do programa STATISTICA for Windows 5.1 (StatSoft., Tulsa - OK, USA, 1996). Na determinação da acurácia e precisão das estimativas visuais foi utilizada análise de regressão linear simples, determinando-se assim os modelos de regressão das avaliações efetuadas visualmente em relação às avaliações reais obtidas com o auxílio do programa Quant, para cada avaliador. Na comparação da acurácia dos dados estimados com os reais utilizaram-se os parâmetros interseção ( $a$ ) e inclinação da reta $(b)$, e na precisão o coeficiente de determinação $\left(R^{2}\right)$. Consideraramse com maior acurácia os avaliadores cujas estimativas 
resultaram em equações de regressão em que os parâmentros "a" e "b" não diferiram estatisticamente de 0 e 1, respectivamente, e com maior precisão os avaliadores cujas estimativas permitiram o ajuste do modelo linear com maiores valores do coeficiente de determinação $\left(R^{2}\right)$.

\section{RESULTADOS}

\section{Escala Diagramática}

Os resultados obtidos através das análises com o programa Quant foram utilizados na construção de um gráfico representando a freqüência da doença em diferentes intervalos de severidade (Figura 1). Observou-se maior freqüência da doença no intervalo de severidade compreendido entre 0,46 e 2,89\%. A severidade máxima encontrada nas 200 folhas avaliadas foi de $49 \%$, enquanto que o valor mínimo apresentado foi de $0,4 \%$. Os níveis intermediários, seguindose a lei de Weber-Fechener, foram ajustados para 1, 2, 4, 8, 16 e 32\% de severidade (Figura 2).

\section{Validação da escala}

No teste de validação da escala tanto o grupo de avaliadores inexperientes quanto o de experientes apresentaram maior precisão nas suas avaliações quando utilizaram a escala diagramática (Tabela 1). Entretanto, para os avaliadores experientes foi observado um menor acréscimo em termos de precisão quando se comparou aos inexperientes, os quais apresentaram maior precisão com o uso da escala. Todos os avaliadores apresentaram estimativas próximas aos valores reais de severidade, determinados com o programa Quant, quando foram utilizadas a escala e uma boa acurácia (pontos bem distribuídos ao longo do eixo zero dos resíduos), indistintamente quanto utilizaram ou não a escala (Figuras 3 e 4). Desse modo, independentemente do avaliador, quando se utilizou a escala, foi observada uma boa estimativa da severidade, com os resíduos se concentrando na faixa inferior a $10 \%$.

\section{Influência do treinamento na acurácia e precisão das avaliações}

Quando submetidos ao treinamento prévio, os avaliadores inexperientes tornaram-se mais precisos, independentemente do uso da escala, embora com a sua utilização foi observado um aumento na precisão, explicando em média, 86\% da variação da avaliação da doença. Para os avaliadores experientes, o treinamento prévio não influenciou o grau de precisão, provavelmente em função do alto nível já conseguido com o grupo antes do treinamento, sendo que em média 89,5\% das estimativas explicaram a variação da mensuração da doença (Tabela 2).

Quanto à acurácia das estimativas, os avaliadores submetidos ao treinamento não apresentaram diferença no desempenho (Tabela 2). Todos os avaliadores apresentaram estimativas próximas aos valores reais de severidade, quando do uso da escala e uma boa acurácia independentemente do uso da escala (Figuras 5 e 6 ).

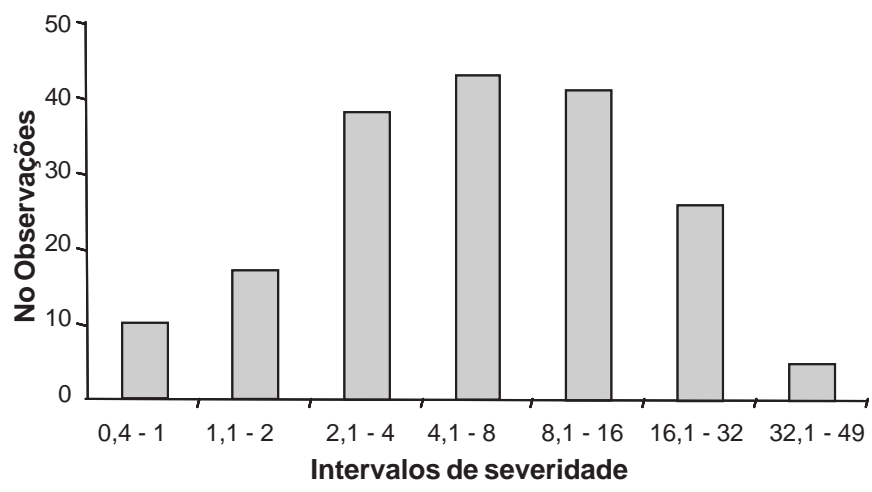

FIG. 1 - Freqüência observada de severidade da mancha foliar em eucalipto (Eucalyptus spp.) causada por Quambalaria eucalypti em diferentes intervalos.
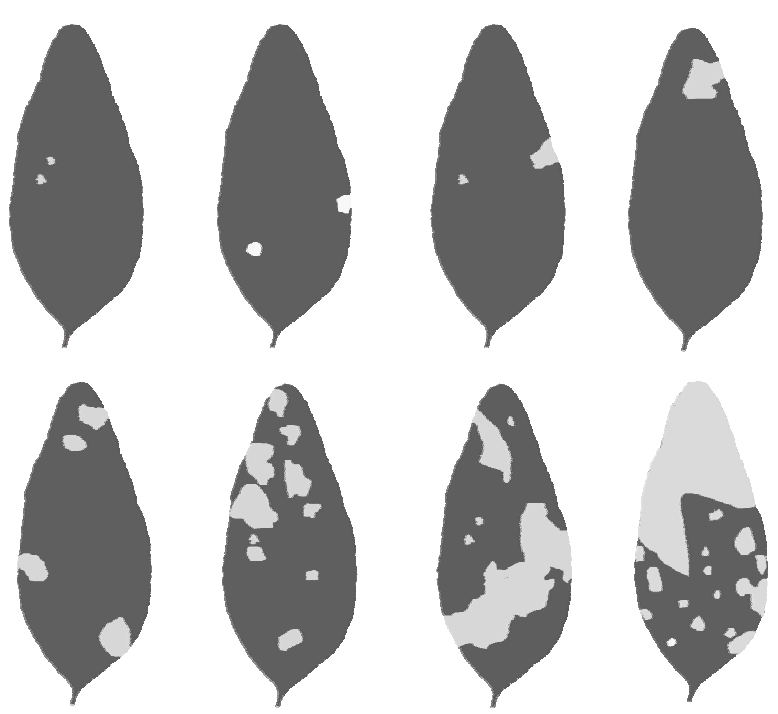

FIG. 2 - Escala diagramática de severidade da mancha foliar do eucalipto (Eucalyptus spp.) causada por Quambalaria eucalypti.

TABELA 1 - Acurácia e precisão representadas pela interseção $(a)$, inclinação $(b)$ e coeficiente de determinação $\left(R^{2}\right)$ nas avaliações da severidade da mancha foliar do eucalipto (Eucalyptus spp.), causada por Quambalaria eucalypti, por avaliadores inexperientes e experientes, sem e com o auxílio da escala diagramática

\begin{tabular}{|c|c|c|c|c|c|c|}
\hline \multirow[b]{2}{*}{ Avaliador } & \multicolumn{3}{|c|}{ Sem escala } & \multicolumn{3}{|c|}{ Com escala } \\
\hline & a & b & $R^{2}(\%)$ & a & b & $R^{2}(\%)$ \\
\hline \multicolumn{7}{|c|}{ Inexperientes } \\
\hline 01 & 0,11 & 0,88 & 79 & 1,49 & 1,05 & 88 \\
\hline 02 & $2,83 *$ & 0,86 & 73 & $4,12 *$ & 0,88 & 74 \\
\hline 03 & 1,39 & 0,75 & 74 & $2,49 *$ & 0,75 & 80 \\
\hline 04 & 2,70 & 0,67 & 61 & $1,79 *$ & 1,10 & 87 \\
\hline \multicolumn{7}{|c|}{ Experientes } \\
\hline 05 & 2,50 & 0,84 & 79 & 0,76 & 0,95 & 87 \\
\hline 06 & $3,05^{*}$ & 0,7 & 77 & 1,17 & 0,7 & 80 \\
\hline 07 & 0,40 & 1,02 & 84 & 1,87 & 0,91 & 86 \\
\hline 08 & 2,03 & 0,85 & 89 & 0,99 & 0,88 & 92 \\
\hline
\end{tabular}

*Parâmetros do modelo linear significativamente diferentes de 0 e 1 para interseção (a) e inclinação (b), respectivamente. 


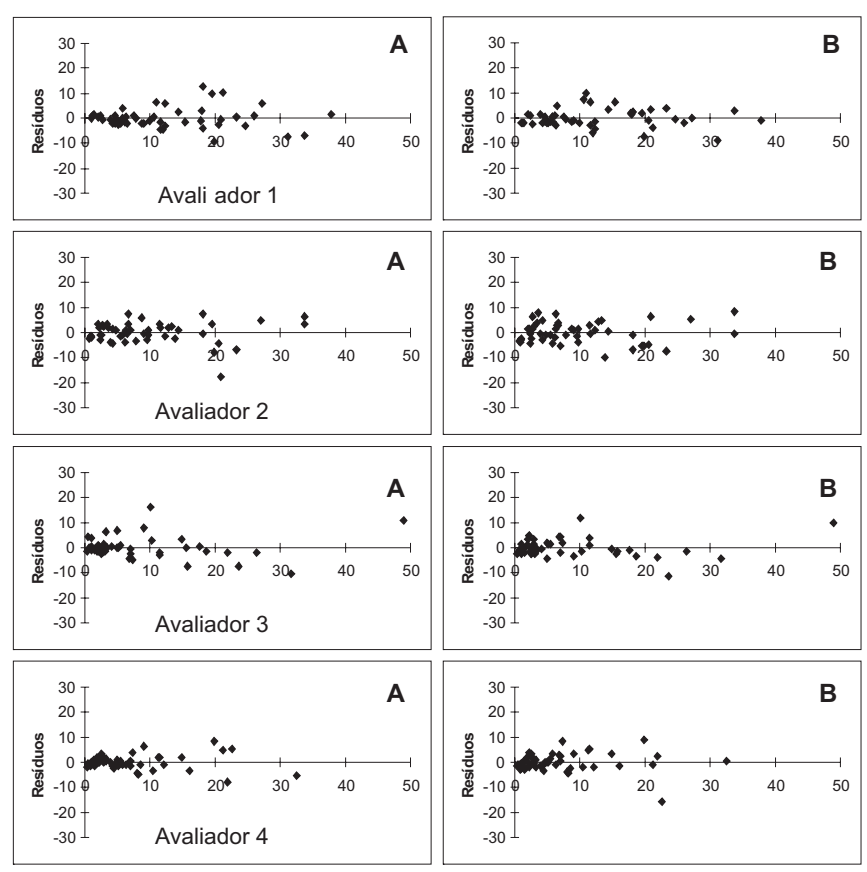

FIG. 3 - Erros absolutos (severidade estimada menos severidade real) sem (A) e com (B) o uso da escala diagramática para avaliadores inexperientes.

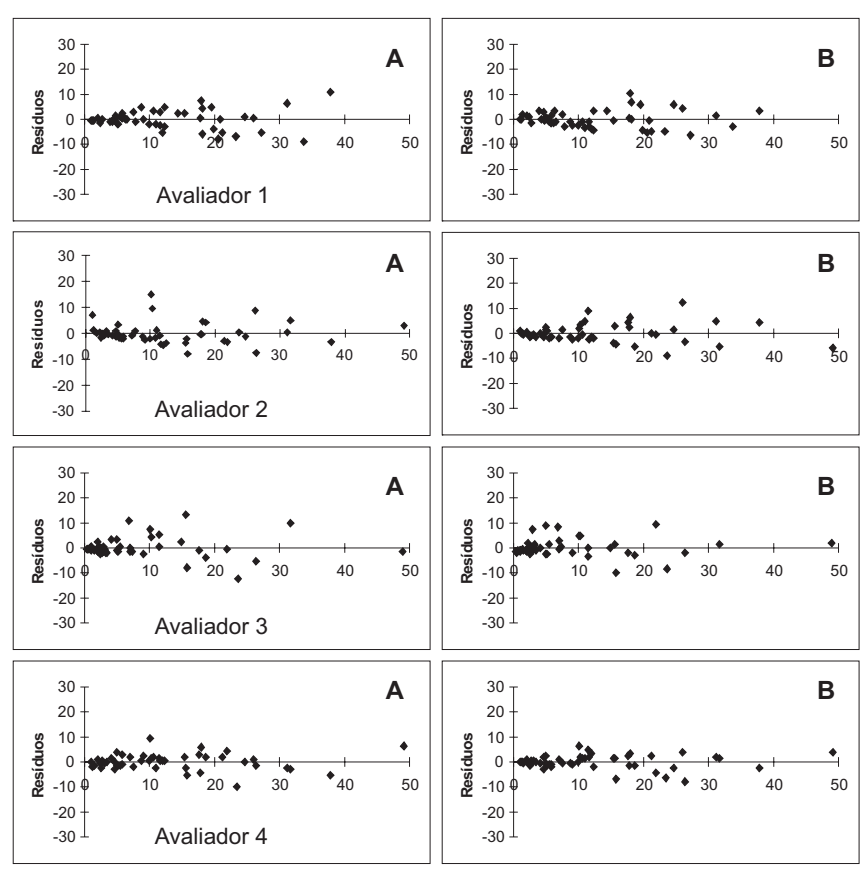

FIG. 4 - Erros absolutos (severidade estimada menos severidade real) sem (A) e com (B) o uso da escala diagramática para avaliadores experientes.

\section{DISCUSSÃO}

A máxima severidade da doença (49,1\%) encontrada no presente trabalho diferiu-se das observações de Kranz
TABELA 2 - Acurácia e precisão representadas pela interseção $(a)$, inclinação $(b)$ e coeficiente de determinação $\left(R^{2}\right)$ nas avaliações da severidade da mancha foliar do eucalipto (Eucalyptus spp.), causada por Quambalaria eucalypti, sem e com o auxílio da escala diagramática, após treinamento prévio dos avaliadores

\begin{tabular}{|c|c|c|c|c|c|c|}
\hline \multirow[b]{2}{*}{ Avaliador } & \multicolumn{3}{|c|}{ Sem escala } & \multicolumn{3}{|c|}{ Com escala } \\
\hline & a & b & $R^{2}(\%)$ & a & b & $R^{2}(\%)$ \\
\hline \multicolumn{7}{|c|}{ Inexperientes } \\
\hline 01 & 1,51 & 0,81 & 86 & 0,69 & 0,92 & 86 \\
\hline 02 & $3,42 *$ & 0,92 & 84 & $3,26^{*}$ & 0,92 & 85 \\
\hline 03 & $6,93^{*}$ & 1,01 & 79 & $4,63^{*}$ & 0,96 & 83 \\
\hline 04 & $2,89^{*}$ & 0,72 & 86 & $2,29 *$ & 1,02 & 90 \\
\hline \multicolumn{7}{|c|}{ Experientes } \\
\hline 05 & 0,92 & 1,02 & 88 & $2,26^{*}$ & 0,98 & 89 \\
\hline 06 & 1,23 & 0,57 & 73 & 0,21 & 0,82 & 85 \\
\hline 07 & $2,61^{*}$ & 0,97 & 91 & $1,60^{*}$ & 0,97 & 94 \\
\hline 08 & $2,81^{*}$ & 0,85 & 84 & 1,20 & 0,92 & 90 \\
\hline
\end{tabular}

*Parâmetros do modelo linear significativamente diferentes de 0 e 1 para interseção (a) e inclinação (b), respectivamente.

(1988) para outros patossistemas, nos quais, a maioria das mensurações, em campo, apresentou níveis abaixo de 30\%. Todavia, ficou claro pelo gráfico de freqüências que existe um decréscimo no número de plantas com severidade superior a $32 \%$.

Para as avaliações visuais da mancha foliar do eucalipto causada por Q. eucalypti, realizadas com o auxílio da escala diagramática, obtiveram-se valores $\left(\mathrm{R}^{2}\right)$ de precisão inferiores a 95\% considerados desejáveis por Kranz (1988), semelhantes ou superiores aos níveis verificados em outros estudos utilizando escalas diagramáticas (Nutter et al., 1993; Michereff et al., 2000; Díaz et al., 2001; Rodrigues et al., 2002).

Os avaliadores foram mais precisos que acurados, analogamente ao observado na quantificação da severidade de doenças em Agrostis palustris Huds. (Nutter et al., 1993), feijoeiro (Stonenhouse, 1994) e inhame (Michereff et al., 2000).

Em níveis mais baixos de severidade $(<10 \%)$, os avaliadores apresentaram estimativas com maior acurácia e precisão, semelhante ao observado em avaliações de escalas em outros patossistemas (Stonehouse, 1994; Godoy et al., 1997; Michereff et al., 2000).

De acordo com Nutter (1989), para que um avaliador possa ser considerado excelente, o erro de suas estimativas deve estar dentro de um intervalo de $\pm 5 \%$ do valor real, e bom quando não ultrapassar a $\pm 10 \%$ (Nutter, 1989). Nesse sentido, tanto os avaliadores experientes quanto os inexperientes foram considerados bons na avaliação da severidade da mancha foliar do eucalipto causada por $Q$. eucalypti. É importante ressaltar que a presença de certo nível de erro absoluto nas mensurações pode ser compensada pela rapidez e padronização quando se utiliza escala diagramática (Stonehouse, 1994).

Avaliadores experientes foram mais precisos e acurados que avaliadores inexperientes, principalmente antes 

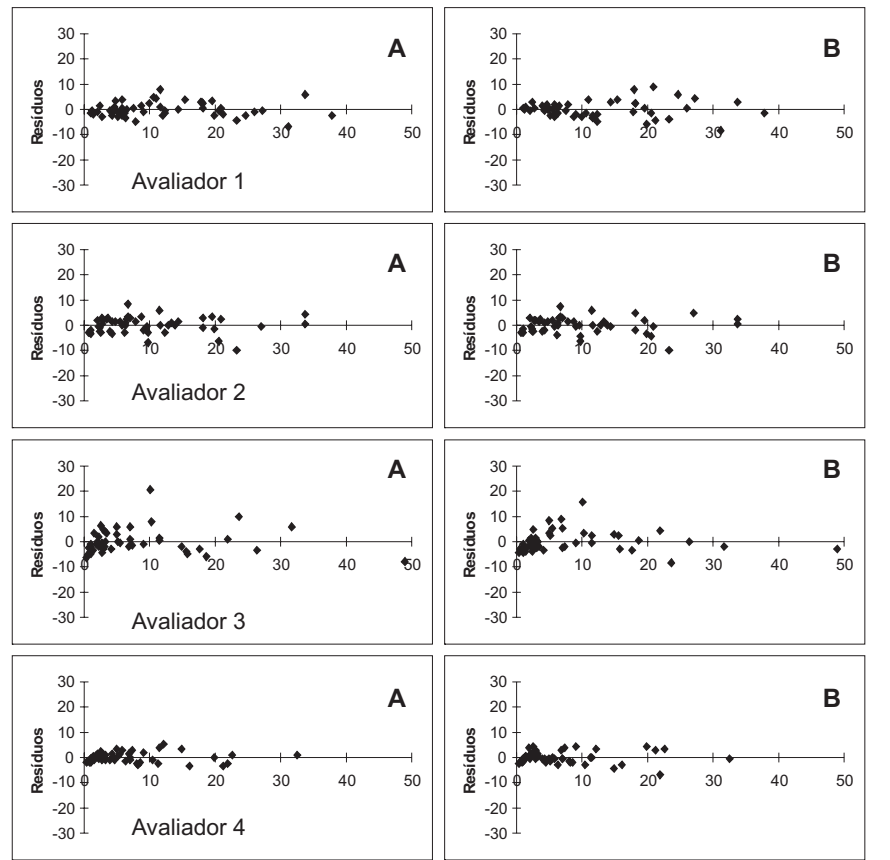

FIG. 5 - Erros absolutos (severidade estimada menos severidade real) sem (A) e com (B) o uso da escala diagramática para avaliadores inexperientes, após treinamento.

do treinamento, conforme já mencionado por Campbell \& Madden (1990). O treinamento teve influência principalmente sobre a precisão das estimativas, confirmando assim observações realizadas em outros estudos (Nutter \& Shultz, 1995; Parker et al., 1995), mas este não é suficiente para eliminar totalmente os erros (Kranz, 1988; Parker et al., 1995).

Os resultados deste estudo permitem concluir que a quantificação da mancha foliar do eucalipto causada por $Q$. eucalypti através da escala diagramática proposta tornou-se rápida, fácil, de boa precisão e acurácia, independentemente da experiência do avaliador, tornando-se uma ferramenta útil na quantificação da doença.

\section{REFERÊNCIAS BIBLIOGRÁFICAS}

ALFENAS, A.C., ZAUZA, E.A.V., ROSA, O.P.P. \& ASSIS, T.F. Sporothrix eucalypti, um novo patógeno do eucalipto no Brasil. Fitopatologia Brasileira 26:221. 2001. (Resumo)

ALFENAS, A.C., ZAUZA, E.A.V, MAFIA, R.G. \& ASSIS, T.F. Clonagem e Doenças do Eucalipto. Viçosa, MG. Editora UFV. 2004.

AMORIM, L., BERGAMIN FILHO, A., SANGUINI, A., CARDOSO, C.O., MORAES, V.A. \& FERNANDES, C.R. Metodologia de avaliação da ferrugem da cana-de-açúcar (Puccinia melanocephala). Boletim Técnico Copersucar 39:13-16. 1987.

AMORIM, L., BERGAMin FILHO, A., PALAzZO, D., BASSANEZI, R.B., GODOY, C.V. \& TORRES, G.A.M. Clorose variegada dos citros: uma escala diagramática para avaliação da
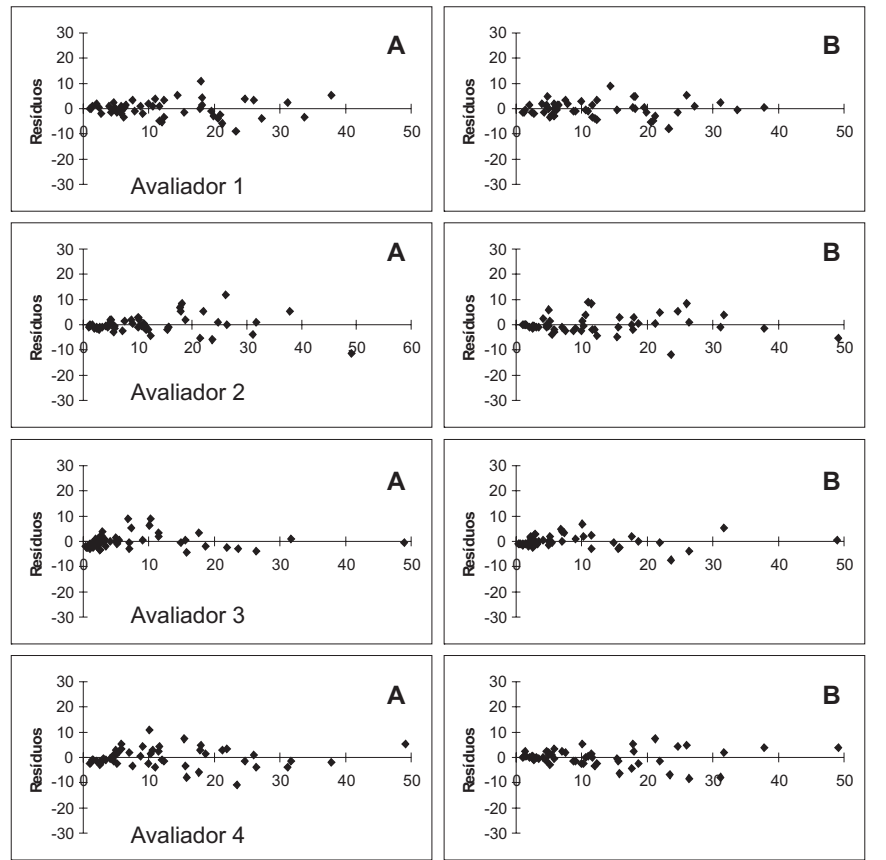

FIG. 6 - Erros absolutos (severidade estimada menos severidade real) sem (A) e com (B) o uso da escala diagramática para avaliadores experientes, após treinamento.

severidade da doença. Fitopatologia Brasileira 18:174-180. 1993.

BERGER, R.D. Measuring disease intensity. In: Teng, P.S. \& Krupa, S.V. (Eds.). Crop Loss Assessment which Constrain Production and Crop Improvement in Agriculture and Forestry. St. Paul. University of Minnesota, 1980. pp.28-31.

BOFF, P., ZAMBOLIM, L. \& VALE, F.X.R. Escalas para avaliação de severidade de mancha de estenfílio (Stemphylium solani) e da pinta preta (Alternaria solani) em tomateiro. Fitopatologia Brasileira 16:280-283. 1991.

CAMPBELL, C.L. \& MADDEN, L.V. Introduction to Plant Disease Epidemiology. New York. John Wiley \& Sons. 1990.

DÍAZ, C.G., BASSANEZI, R.B. \& BERGAMIN FILHO, A. Desenvolvimento e validação de uma escala diagramática para Xanthomonas axonopodis pv. phaseoli em feijoeiro. Summa Phytopathologica 27:35-39. 2001.

DUVEILLER, E. A pictorial series of disease assessment keys for bacterial leaf streak of cereals. Plant Disease 78:137-141. 1994.

GAUNT, R.E. Measurement of disease and pathogens. In: Teng, P.S. (Ed.) Crop Loss Assessment and Pest Management. St. Paul, APS Press, 1987. pp.6-18.

GAUNT, R.E. The relationship between plant disease and severity and yield. Annual Review of Phytopathology 33:119-144. 1995.

GODOY, C.V., CARNEIRO, S.M.T.P., IAMAUTI, M.T., PRIA, M.D., AMORIM, L., BERGER, R.D. \& BERGAMIN FILHO, A. Diagrammatic scales for bean diseases: Development and validation. Journal of Plant Disease and Protection 104:336-345. 1997.

GONÇALVES, R.C. Etiologia da mancha bacteriana de Eucalyptus spp. no Brasil. (Tese de Doutorado). Viçosa. Universidade Federal de Viçosa. 2003.

HORSFALL, J.G. \& BARRAT, R.W. An a improved grading system 
for measuring plant disease. Phytopathology 35:655. 1945.

HORSFALL, J.G. \& COWLLING, E.B. Pathometry: The measurement of plant disease. In: Horsfall, J.G. \& Cowlling, E.B. (Eds.) Plant Disease: An Advanced Treatise - How Disease Develops in Populations. New York, Academic Press. 2:119-136. 1978.

JAMES, W.C. An illustrated series of assessment keys for plant diseases, their preparation and usage. Cannadian Plant Disease Survey 51:39-65. 1971.

JAMES, W.C. \& TENG, P.S. The quantification of production constrains associated with plant diseases. Applied Biology 4:210267. 1979.

JUNGHANS, D.T., ALFENAS, A.C. \& MAFFIA, L.A. Escala de notas para quantificação da ferrugem em Eucalyptus. Fitopatologia Brasileira 28:184-188. 2003.

KRANZ, J. Measuring Plant Disease. In: Kranz, J. \& Rotem, J. (Eds.) Experimental Techniques in Plant Disease Epidemiology. Berlim, Springer Verlag. 1988. pp.35-50.

MICHEREFF, S.J., MAFFIA, L.A. \& NORONHA, M.A. Escala diagramática para avaliação da severidade da queima das folhas do inhame. Fitopatologia Brasileira 25:612-619. 2000.

MORA-BRENES, B. Estimativa de perdas no rendimento de feijão comum (Phaseolus vulgaris L.) causada pela mancha angular (Isariopsis griseola Sacc.). (Tese de Mestrado). Viçosa. Universidade Federal de Viçosa. 1989.

NEWTON, A.C. \& HACKETT, C.A. Subjective components of mildew assessment on spring barley. European Journal of Plant Pathology 100:395-412. 1994.

NUTTER JR., F.W. Disease Pro: a computer program for evaluating and improving a person ability to assess disease proportion. Phytopathology 29:1135. 1989.

NUTTER JR., F.W., GLEASON, M.L., JENCO, J.H. \& CHRISTIANS, N.C. Assessing the accuracy, intra-rater repetibility of disease assessment systems. Phytopathology 83:806-812. 1993. NUTTER JR., F.W. \& SCHULTZ, P.M. Improving the accuracy and precision of disease assessment: Selection of methods and use of computer-aided training programs. Canadian Journal of Plant Pathology 17:174-178. 1995.

O’BRIEN, R.D. \& VAN BRUGGEN, A.H.C. Accuracy, precision, and correlation to yield of disease severity scales for corky root of lettuce. Phytopathology 82:91-96. 1992.

PARKER, S.R., WHELAN, M.J. \& ROYLE, D.J. Reliable measurement of disease severity. Aspects of Applied Biology 43:205-214. 1995.

RODRIGUES, J.C.V., NOGUEIRA, N.L. \& MACHADO, M.A. Elaboração e validação de uma escala diagramática para leprose dos citros. Summa Phytopathologica 28:192-196. 2002.

RORHBACH, K.G. \& SCHMITT. Pineapple. In: Ploetz, R.C., Zentmyer, G.A., Nishijima, W.T., Rohrbach, K.G. \& Ohr, H.D. (Eds). Compendium of tropical fruit diseases, APS Press, St. Paul, 1994. pp.45-55.

SARTORATO, A. Resistência vertical e horizontal do feijoeiro comum a Isariopsis griseola Sacc. (Tese de Doutorado). Piracicaba. Universidade de São Paulo. 1989.

STONEHOUSE, J. Assessment of Andean bean disease using visual keys. Plant Pathology 43:519-527. 1994.

TOMERLIN, J.R. \& HOWELL, T.A. Distrain: A computer program for training people to estimate disease severity on cereal leaves. Plant Disease 72:455-459. 1988.

VALE, F.X.R., FERNANDES FILHO, E.I. \& LIBERATO, J.R. QUANT. A software plant disease severity assessment. $8^{\text {th }}$ International Congress of Plant Pathology, Christchurch New Zealand, 2003. p.105.

ZADOKS, J.C. Methodology of epidemiological research. Annual Review of Phytopathology 10:253-276. 1972. 